\title{
An Effective Plant Design for Extracting Thorium from Rare Earth Minerals and its Schematic Construction
}

\author{
Anuvinda P.S ${ }^{1}$, Harish Bakker ${ }^{2}$, Jishnu $\mathrm{S}^{3}$, Musthafa $\mathrm{N}^{4}$, Suchithra $\mathrm{K}^{\mathbf{5}}$, K Neethu Sathyan ${ }^{6}$ \\ UG Scholar, Applied Electronics and Instrumentation, IES College of Engineering, Thrissur, India 1, 2, 3,4,5 \\ Asst. Professor, Electronics and Communication Engineering, IES College of Engineering, Thrissur, India ${ }^{6}$
}

\begin{abstract}
In this research paper we are proposing a method for extracting Thorium from rare earth minerals in the form of Thoria. It is found that the occurrence of Thorium in the earth is abundant than Uranium, then also the rate of extraction of Thorium, is minimal now a days. There are chemical reactions that can yield almost hundred percentage of Thorium as an extracted process but there is no formal industrial level of extraction process happening nowa days. In this paper we are proposing a process which can achieve almost $99.99 \%$ of thorium extraction from the earth minerals in industrial level.
\end{abstract}

Keywords: Process Flow Diagram (PFD), Piping and Instrumentation Diagram (P\&ID).

\section{I.INTRODUCTION}

Radioactive actinide metal, Thorium (Th) discovered in 1829 has the longest half-life of all the significantly radioactive elements, 14.05 billion years. Thorium is estimated to be about three to four times more abundant than Uranium in the Earth's crust, and is refined from monazite sands as a by-product of extracting rare earth metals. Thorium fuels results in a safer and better performing reactor core because Thoria has a higher melting point, higher thermal conductivity, and lower coefficient of thermal expansion than the now-common fuel Uranium dioxide (UO2). Even though the occurrence of Thorium in the earth is abundant than Uranium, the rate of extraction of Thorium, is minimal now a days. There are chemical reactions that would yield almost hundred percentage of Thorium as an extracted process but there is no formal industrial level of extraction process happening now days.

We are proposing a effective virtual construction of Thorium extraction plant that can extract Thorium from rear earth minerals. The international standard for representing the plant layout is in the form of piping \& instrumentation diagram (P\&ID). From P\&I diagrams we can easily find out the process and every data about the devices and components in the process.

\section{II.EXISTING METHOD}

In conventional method, the Monazite beach sands are mined using procedures with placer mining equipment. The monazite is then mixed with some other minerals like silica, zircon, magnetite, ilmenite and garnet. The required Concentration is obtained by washing out the lighter minerals and the separation of the monazite is obtained by passing the resulting monazite fraction through a series of electromagnetic separators by virtue of difference in their magnetic permeability property. In the convention method, thorium is being partially separated from the rare earths by adding $\mathrm{NaOH}$ to the acidic chloride solution. The purification in the final stage is done by solvent extraction method where the crude thorium hydroxide precipitate is being dissolved in nitric acid.

\section{III.PROPOSED SYSTEM}

The processing of monazite leads to the generation of concentrates containing Thorium (Th), Uranium (U) and phosphate (PO43).Monazite is then cracked through processing with concentrate sulphuric acid (H2SO4) where liquor containing Th and $\mathrm{U}$ is also generated. Mechanisms for Thorium extraction by amines were proposed by Schmidt in 1971.

Continuous extraction and stripping processes were carried out after selecting the best conditions for the process. The continuous counter-current experiments were carried out in a sequence of mixer-settler stages, with mixers of $70 \mathrm{~mL}$ 
and settlers of $260 \mathrm{~mL}$. In the experiment, four extraction stages and five stripping stages were done for $32 \mathrm{~h}$. The extraction stage consist of the reaction between sulphuric liquor containing Thorium with Primene JM-T of concentration the $0.15 \mathrm{~mol} / \mathrm{L}$ which is carried out in four stages for a time of 5 minutes in a mixer. In the stripping stage contains the reaction between the output of the extraction unit with hydrochloric acid of concentration $2.0 \mathrm{~mol} / \mathrm{L}$ is carried out in five stages for a time period of 9.8 minutes in a mixer. The control of the system stability was evaluated through the determination of Thorium in the exit flows every hour.

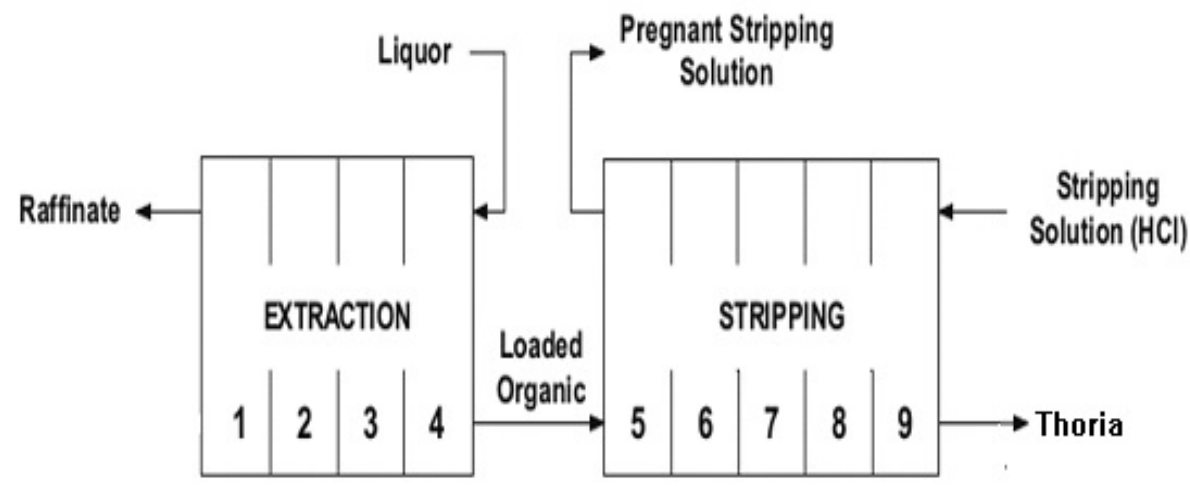

Fig 1 Flow diagram illustrating the successive extraction and stripping stages

The Fig 1 is the flow diagram illustration of the stripping and extraction process of Thorium. This is a continuous process with the input being provided to the extraction process and output being taken from the stripping process. The extraction process is being fed with a known amount of sulphur liquor whereas the stripping phase is being fed with stripping solution $(\mathrm{HCl})$.

\section{III.PROCESS FLOW DIAGRAM}

Process flow diagrams or simply PFD are mainly used in chemical process engineering. This represents the flow of chemicals and the equipment involved in the particular process. The Fig 2 illustrates the complete process flow diagram of the process being considered. The process flow diagram can be split up in to four parts according to the process being carried out in each section. The four sections are material handling unit, pretreatment unit, extraction unit and stripping unit. Each section has its own characteristic identity.

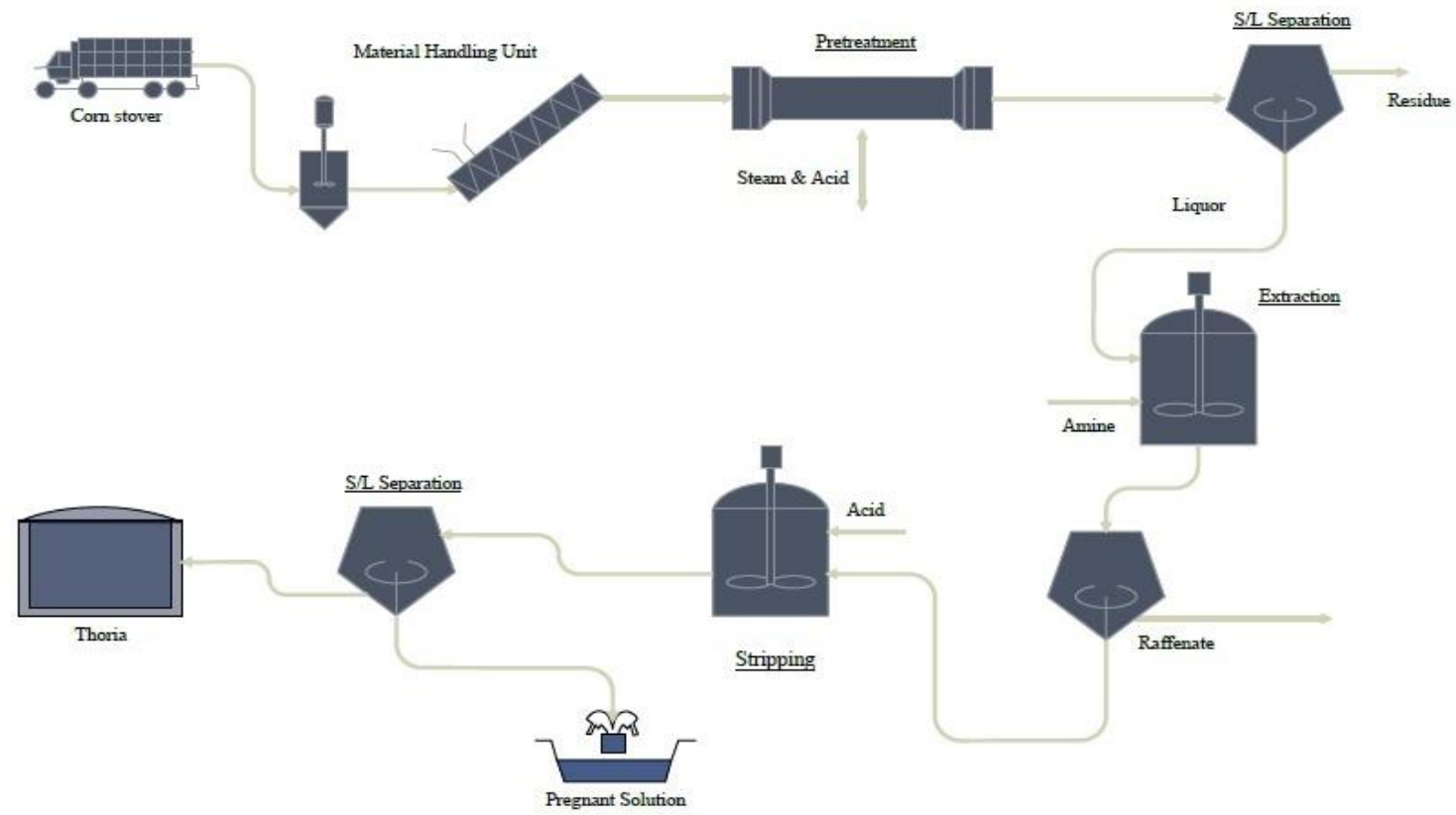

Fig 2 Process Flow Diagram of Thorium Extraction 
Vol. 5, Issue 4, April 2017

The material handling unit being the area where all the required materials for the process are stored and supplied contains a provision for then transportation, storage and pulverizing. The first section in the figure 1 depicts the material handling unit of the process under construction. The pretreatment area should have equipment that can facilitate the reaction of Sulphuric acid and the Monazite sand at 120 - 150 degree Celsius. Hence the process flow diagrams consider this point as a cylindrical kiln which can be used for the same. With the supply of stream and acid to the kiln as the supplementary inputs along with the material (Monazite) the pretreatment will be done as expected. The output of the kiln is then supplied to a filter to separate the liquor from the residue. The second section of figure depicts the pretreatment unit. The extraction and stripping stages of the process flow diagrams contains the same equipment's as depicted in the third and fourth section of the figure. The process since being the mixing of the reactants, a mixer is a mandatory requirement in the process flow diagram to illustrate the flow. Since the reaction have the byproducts like raffinate in the extraction stage and the pregnant solution in the stripping stage a filter should be used to filter out the solution of interest. Finally Thoria, the output of the stripping stage is stored in a storage tank.

\section{IV.PLANT LAYOUT}

The design of a plant depends greatly on the basic equipment list and the interconnection between the equipment and further details. The figure 3 illustrates the plant layout of the pretreatment and the material handling unit of the proposed Thorium extraction plant using Primene JM-T. Similarly we have developed the plant layout for extraction and stripping stages.

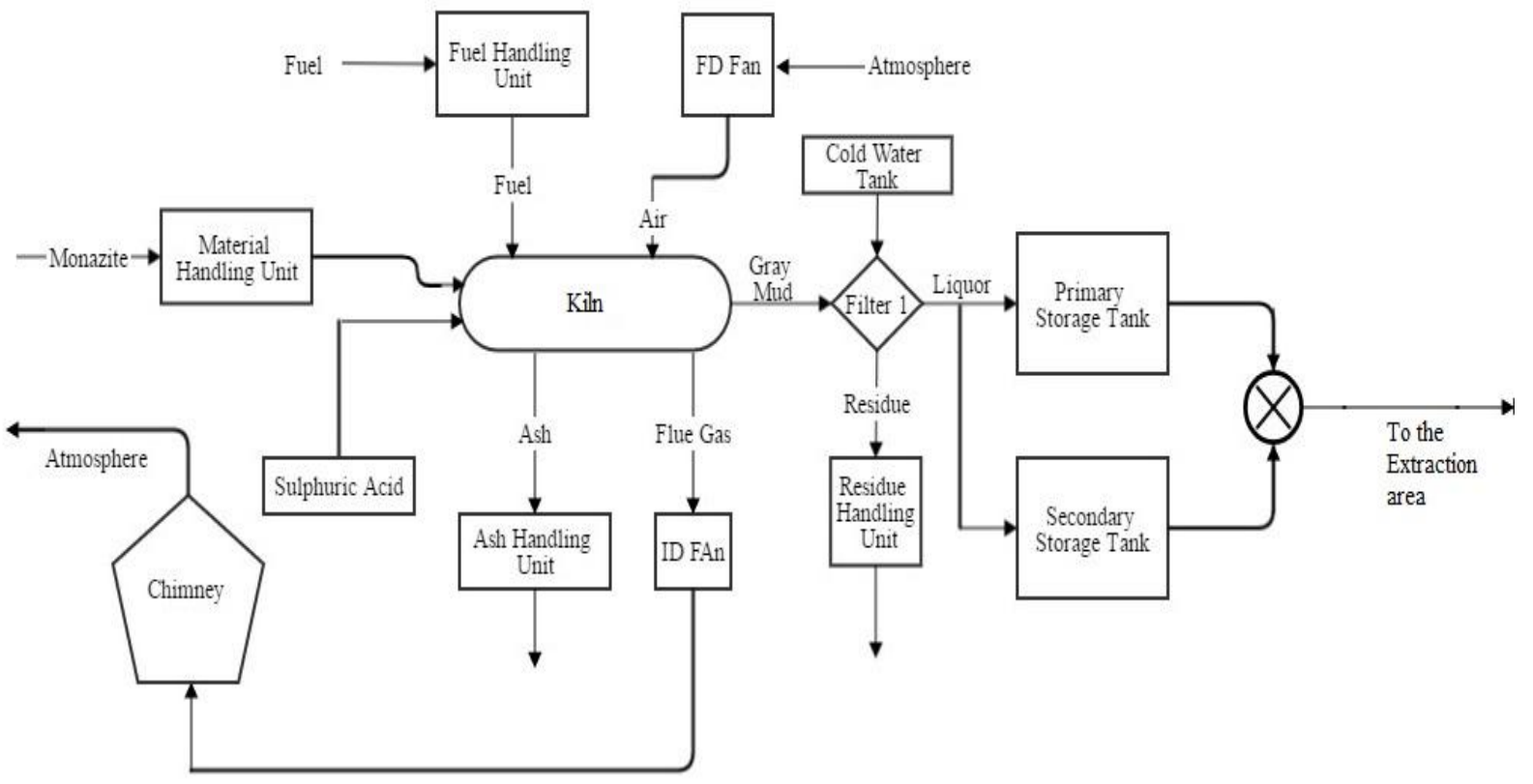

Fig 3 Plant layout of Pretreatment and Material handling unit

\section{AUTOCAD P\&ID}

A Piping and Instrumentation Diagram - P\&ID gives schematic illustration of the functions of piping, instrumentation and system equipment components. The P\&ID is based on the Process Flow Diagram (PFD), represents the technical realization of a process by means of graphical symbols for equipment and piping as well as graphical symbols for process measurement and control functions. The schematic construction of the plant is done through the creation of the piping and instrumentation layout. Compared to the traditionally time consuming process, Autodesk AutoCAD P\&ID 2016 software enables process plant, piping and instrumentation designers to improve their productivity. If there is any design change Intelligent lines that break on symbol insertion and automatically heal while maintaining defined flow direction. Some of the main features of the software are as follows:

- Interoffice collaboration with vault

- Standard symbol library

- Faster report generation

- ISO 15926 standards 
IJIREEICE

Vol. 5, Issue 4, April 2017

AutoCAD P\&ID software is a standalone platform built on an AutoCAD platform and is also included in the Autodesk Architecture, Engineering \& Construction Collection, where it can be linked with a range of other AutoCAD products.

\section{SCHEMATIC CONSTRUCTION USING AUTOCAD P\&ID}

The virtual schematic construction of thorium extraction plant is done in terms of Piping and Instrumentation Diagram with the help of the software Autodesk is as shown:

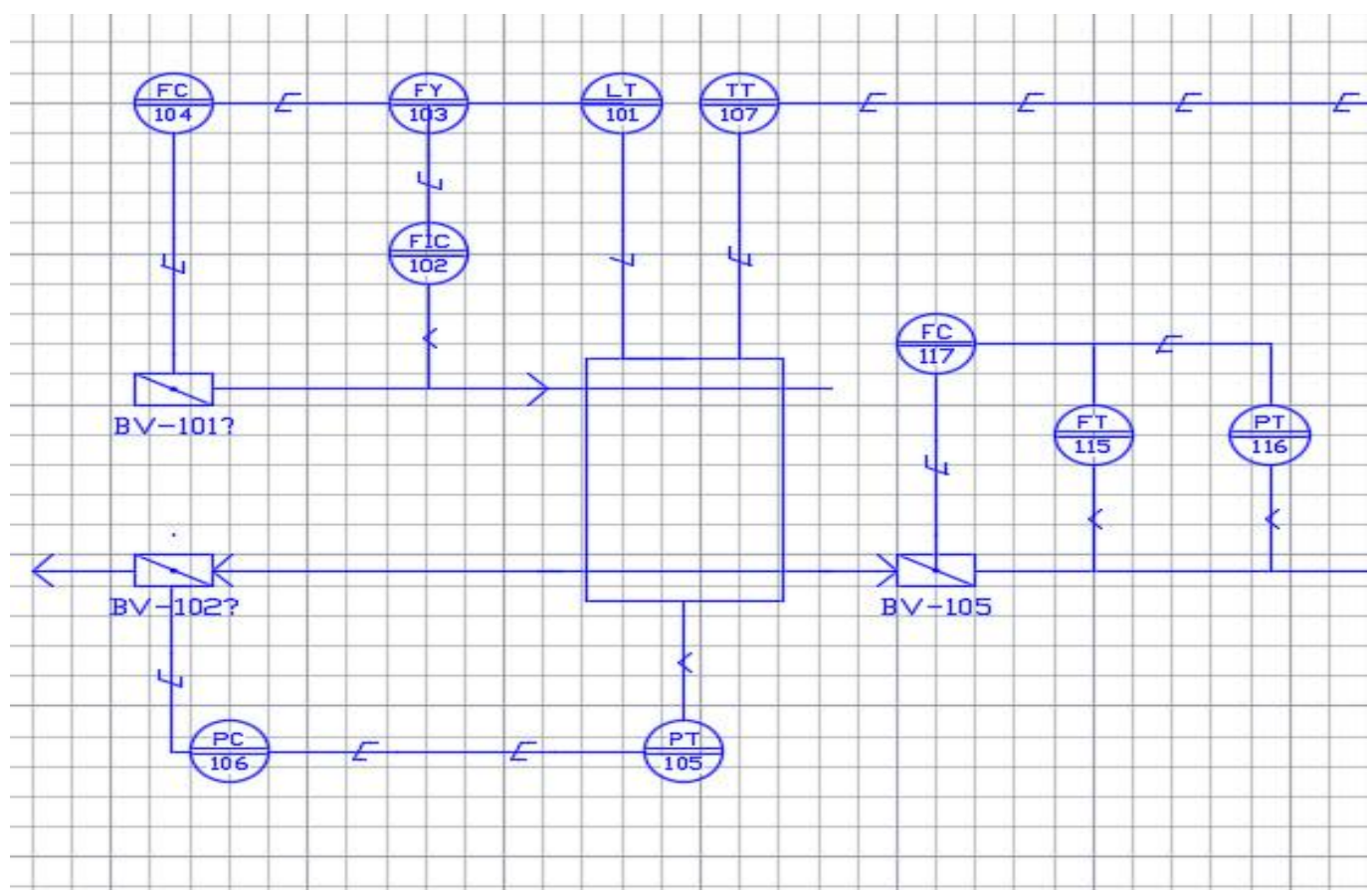

Fig 4 P\&ID layout of a tank

Figure 4 illustrates the simple P\&ID of a tank. The figure also depicts the necessity of three control loops. The temperature of the tank also is monitored all day long. The figure 5 represents the simple P\&ID layout of a mixer which is important equipment in Extraction and Stripping stage of the Thorium Extraction Plant. The figure depicts two control loops that are necessary for the proper functioning of the mixer. Output flow of the mixer and the pressure inside the mixer should also be monitored all day long. Similarly we have developed the full schematic representation of the entire plant using Autocad P\&ID.

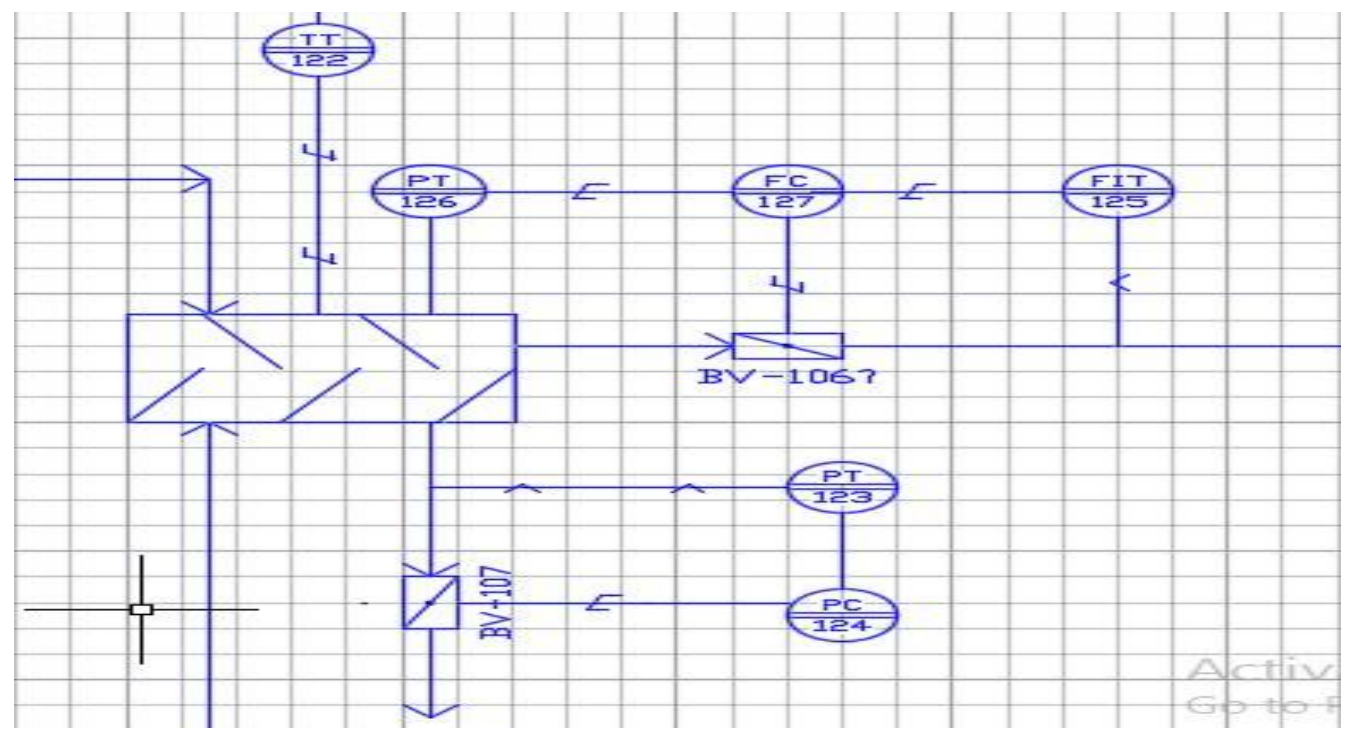

Fig 5 P\&ID layout of a mixer 


\section{IJIREEICE \\ International Journal of Innovative Research in \\ Electrical, Electronics, Instrumentation and Control Engineering \\ ISO 3297:2007 Certified \\ Vol. 5, Issue 4, April 2017}

\section{CONCLUSION}

This project titled "An Effective Plant Design for Extracting Thorium from Rare Earth Minerals and Its Schematic Construction" is a new concept that can replace the current Uranium used Nuclear Power Plants. From the literature survey it was found that even though Thorium is abundant than Uranium and there are chemical reactions that would yield almost hundred percentage of Thorium as an extracted process, still there is no formal industrial level of extraction process happening. So we proposed Virtual construction of a plant that can extract Thorium from rare earth minerals. The project implementation constitutes different stages like Process Identification, Process Flow Diagram, and Plant Layout etc. The designing of the plant was done using piping and instrumentation diagram(P\&ID) which is the basis layout used by engineers for the identification of various aspects of a process. P\&ID was simulated using Autodesk AutoCAD P\&ID software.

\section{REFERENCES}

[1] Thorium and Uranium extraction from rare earth elements in monazite sulfuric acid liquor through solvent extraction by Janubia C.B.S Amaral and Carlos A. Morais

[2] Piping and instrumentation diagram (P\&ID) project standards and specification by KLM Technology Group

[3] DOE handbook - Chemical process hazard analysis by U.S. Department of Energy Washington, D.C. 20585

[4] Control loop foundation: batch and continuous processes by Terrence Blevins and Mark Nixon.

\section{BIOGRAPHIES}
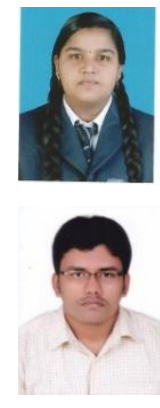

Harish Bakker currently pursuing the Bachelor's degree in Applied Electronics \& Instrumentation Engineering from the IES College of Engineering, Thrissur

Anuvinda P S currently pursuing the Bachelor's degree in Applied Electronics \& Instrumentation Engineering from the IES College of Engineering, Thrissur.

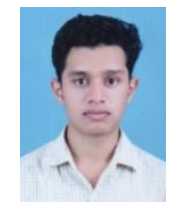

Jishnu S currently pursuing the Bachelor's degree in Applied Electronics \& Instrumentation Engineering from the IES College of Engineering, Thrissur

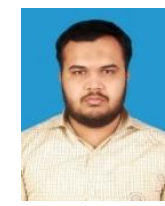

Musthafa N currently pursuing the Bachelor's degree in Applied Electronics \& Instrumentation Engineering from the IES College of Engineering, Thrissur

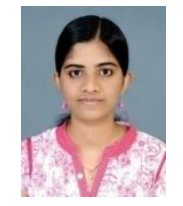

Suchitra K currently pursuing the Bachelor's degree in Applied Electronics \& Instrumentation Engineering from the IES College of Engineering, Thrissur

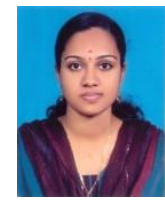

K Neethu Sathyan received the Bachelor's degree from Kerala University and Master's Degree in Instrumentation Engineering from Anna University,Chennai. She is currently working as an Assistant Professor at IES College of Engineering, Thrissur, Kerala, India. Her interest field of research is Automation and Control Systems 